ISSN (Print) : :1412-7601

ISSN (Online) : 2654-8712

Volume 5, No.1 Maret 2019

http://www.ekonobis.unram.ac.id

EKONOBIS

\title{
Analisis Kecenderungan Penduduk Lanjut Usia Berpartisipasi Dalam Pasar Kerja Di Kota Mataram
}

\section{Gusti Ayu Arini, Ida Ayu Putri Suprapti}

Universitas Mataram

\begin{tabular}{l|l}
\hline ARTICLE IN F O & Received : 2 Februari 2019; Accepted: 28Februari 2019; Published: Maret 2019 \\
\hline & ABSTRACT :The phenomenon of the increase in the elderly population in Mataram City
\end{tabular}

Keywords :

Education, Health, Marital

Status, Number of

Dependents, Sex,

Retirement, Elderly

Population
ABSTRACT :The phenomenon of the increase in the elderly population in Mataram City from year to year with increasing life expectancy and the large number of elderly people participating in informal labor markets changes the paradigm of the elderly population who are seen as helpless, sickly and burdened in development become residents who can become development assets. This research is extended to analysis the influence of factors of education, health, marital status, number of dependents, gender and retirement of the elderly population choosing to participate in the labor market in the Mataram City. The type of this research is explanatory research and the number of respondents is 60 people. The analysis model in this study uses the Logistic Regression Model (MRL).The research findings show the health condition of the elderly and the existence of retirement benefits or retirement are the main considerations in deciding to participate in the labor market in the Mataram City, in addition to other variables such as education, marital status, number of dependents, and gender. In general, the health conditions of elderly respondents in the Mataram City are in a healthy condition with a considerable amount of working hours (more than 35 hours per week), the type of elderly respondents working is more in the informal sector and the income received by elderly respondents on average exceeds the minimum wage of the city of Mataram.
Kata Kunci :

Pendidikan, Kesehatan,

Status Perkawinan,

Jumlah Tanggungan,

Jenis Kelamin dan

jaminan Hari Tua

(pensiun), Penduduk Lanjut Usia(Lansia)

ABSTRAK: Fenomena bertambahnya jumlah penduduk lansia di kota Mataram dari tahun ketahun dengan usia harapan hidup yang semakin meningkat dan masih banyaknya penduduk lansia yang berpartisipasi dalam pasar kerja yang informal merubah paradigma terhadap penduduk lansia yang dipandang sebagai penduduk yang tak berdaya, sakit-sakitan dan beban dalam pembangunan menjadi penduduk yang dapat menjadi aset pembangunan.Penelitian ini ditujukan untuk menganalisis pengaruh faktor pendidikan, kesehatan, status perkawinan, jumlah tanggungan, jenis kelamin dan jaminan hari tua (pensiun) penduduk lansia memilih berpartisipasi dalam pasar kerja di kota Mataram. Jenis penelitian yang digunakan adalah penelitian eksplanatif dan jumlah responden 60 orang. Model analisis dalam penelitian ini menggunakan Model Regresi Logistik (MRL). Temuan penelitian ini menunjukkan bahwa kondisi kesehatan lansia dan adanya jaminan hari tua atau pensiunan menjadi pertimbangan yang utama dalam memutuskan berpartisipasi dalam pasar kerja di kota Mataram, disamping variabel lain seperti pendidikan, status perkawinan, jumlah tanggungan, dan jenis kelamin. Secara umum kondisi kesehatan responden lansia di kota Mataram berada dalam kondisi sehat dengan curahan jam kerja yang cukup panjang (lebih dari 35 jam perminggu), jenis pekerjaan responden lebih banyak pada sektor informal dan pendapatan yang diterima oleh responden lansia secara rata-rata melebihi upah minimun kota Mataram .

Corresponding Author :

Alamat : Program Studi Ekonomi Pembangunan, Fakultas Ekonomi dan Bisnis, Universitas Mataram, Jln. Majapahit No. 62 Mataram.

e-mail: gstarini@unram.ac.id 


\section{PENDAHULUAN}

\section{Latar Belakang}

Ageing population atau penuaan penduduk menurut United Nation adalah fenomena yang terjadi ketika umur median penduduk dari suatu wilayah atau negara mengalami peningkatan yang disebabkan oleh bertambahnya tingkat harapan hidup atau menurunnya tingkat fertilitas. Meningkatnya tingkat harapan hidup dan menurunnya tingkat fertilitas ini merupakan suatu keberhasilan bersama dari beberapa aspek, seperti penurunan tingkat kematian bayi, perbaikan akses terhadap pendidikan, bertambahnya lowongan pekerjaan, peningkatan kesetaraan gender, gencarnya program kesehatan produksi, dan terlebih lagi semakin terjangkaunya fasilitas kesehatan untuk sebanyak mungkin masyarakat. Kesemua faktor tersebut berkontribusi dalam menaikkan tingkat harapan hidup ((UN,2015) Heryanah)

Penuaan penduduk yang terkait dengan variabel demogerafi ditandai dengan umur penduduk yang sudah memasuki 60 tahun. Umur 60 tahun ke atas dalam komposisi dan strukur penduduk dikategorikan sebagai penduduk lanjut usia (Lansia).
Jumlah penduduk lansia di Indonesia cukup besar, tahun 2010 sebanyak 18 juta jiwa dan akan meningkat menjadi 30 juta jiwa pada tahun 2025. Diperkirakan pada tahun 2030 akan menembus 40 juta jiwa yang melampaui jumlah penduduk usia dibawah 15 tahun pada masa yang sama (Bondan Sikoki,2013)

Berdasarkan hasil Survei Angkatan Kerja Nasional (SAKERNAS) tahun 2009, ditemukan bahwa sebanyak 47,44 persen lansia Indonesia masih bekerja, 0,41 persen sedang mencari pekerjaan, 27,88 persen mengurus rumah tangga, dan kegiatan lainnya sekitar 24,27 persen. Tingginya persentase lansia bekerja menunjukkan bahwa lansia masih mampu bekerja secara produktif untuk membiayai kehidupan rumah tangganya, namun di sisi lain dapat mengindikasikan bahwa tingkat kesejahteraan lansia masih rendah, sehingga lansia masih harus bekerja (Andini dkk, 2011)

Studi Asesmen Kota Ramah Lanjut Usia 2013 dilakukan di 14 kota di Indonesia yaitu Surabaya, Bandung, Semarang, Makassar, Mataram, Yogyakarta, Denpasar, Balikpapan, Payakumbuh, Depok, Surakarta, Malang dan jakarta. Kota Mataram masuk kualifikasi kota sedang atau menengah di antara 14 kota wilayah studi. Populasi 
lanjut usia Kota Mataram cukup tinggi. Menurut Sensus 2010, jumlah lanjut usia $60+$ kota Mataram mencapai 6\%. Hal ini dipengaruhi, salah satunya, dengan semakin meningkatnya usia harapan hidup, di mana usia harapan hidup Kota Mataram sudah mencapai 65 tahun. Disamping itu, urbanisasi dan persentase penduduk di kota juga mengalami peningkatan pesat di Indonesia, termasuk di Kota Mataram. Urbanisasi terjadi sebagai pengaruh dari tiga hal yaitu pertumbuhan alami, perpindahan dari perdesaan ke perkotaan, dan perubahan klasifikasi pedesaan ke perkotaan.

Jumlah penduduk lansia di Kota Mataram dari tahun ketahun mengalami peningkatan. Tahun 2014 jumlah penduduk lansia sebanyak 27.670 jiwa (12.368 laki-laki dan 15.302 prempuan). Tahun 2015 meningkat menjadi 28.868 jiwa (12.876 laki-laki dan 15.992 prempuan) Selanjutnya tahun 2016 jumlah penduduk lansia mengalami peningkatan menjadi 30.133 jiwa (13.425 laki-laki dan 16.708 prempuan.) (BPS kota Mataram)

Mencermati fenomena diatas dengan masih banyaknya penduduk lansia yang berpartisipasi dalam pasar kerja terutama pada sektor informal menunjukkan penduduk lansia merupakan aset dalam pembangunan yang tetap dapat mengaktualisasikan dirinya dalam usia senja dengan segala keterbatasannya. Kualitas penduduk lansia dicerminkan dengan tingkat pendidikan yang pernah ditempuhnya, kondisi kesehatan dan ekonominya. Pendidikan dapat diartikan sebagai suatu upaya untuk mengembangkan potensi manusi sehingga mempunyai kemampuan untuk mengelola sumber daya alam yang tersedia untuk mewujudkan kesejahteraan rakyat. (Soekidjo,2009). Kondisi kesehatan Lansia sangat terkait dengan tingkat produktivitasnya. Penduduk lansia dalam kondisi yang sehat akan mempunyai produktivitas yang lebih tinggi dibandingkan dengan penduduk lansia yang sakit-sakitan. Terkait dengan ekonominya dalam hal ini pendapatannya, penduduk lansia yang mempunyai pendapatan yang tinggi cenderung untuk mensubstitusi waktu bekerja dengan leisure.

Status perkawinan sebagai bagian dari karakteristik sosial umumnya meliputi kategori belum kawin, kawin, cerai dan janda atau duda. Pada penduduk lansia biasanya status perkawinan ini berkaitan erat dengan partisipasi mereka untuk bekerja. Status kawin dengan jumlah tanggungan keluarga yang besar 
mendorong penduduk lansia banyaknya penduduk lansia yang mencurahkan waktnya bekerja guna berpartisipasi dalam pasar kerja yang memperoleh pendapatan untuk membiayai kebutuhan konsumsi anggota keluarga yang ditanggungnya.

Penduduk lansia yang dulunya bekerja pada lembaga-lembaga formal biasanya akan memperoleh tunjangan hari tua berupa pensiun yang diterima setiap bulannya. Adanya jaminan atau tunjangan hari tua yang diterima dari pemerintah atau lembaga tempatnya bekerja dahulu akan sangat berguna bagi penduduk lansia dalam memenuhi kebutuhan hidupa bersama keluarganya. Kondisi ini juga akan mempengaruhi partisipasi penduduk lansia pada pasar kerja.

Menurut Sensus 2010, jumlah lanjut usia 60+ kota Mataram mencapai 6 persen. Hal ini dipengaruhi, salah satunya, dengan semakin meningkatnya usia harapan hidup, di mana usia harapan hidup Kota Mataram sudah mencapai 65 tahun .Disamping itu, urbanisasi dan persentase penduduk di kota juga mengalami peningkatan pesat di Indonesia, termasuk di Kota Mataram..

Fenomena bertambahnya jumlah penduduk lansia di kota Mataram dari tahun ketahun dengan usia harapan hidup yang semakin meningkat dan masih informal. Fenomena ini merubah paradigma terhadap penduduk lansia yang dipandang sebagai penduduk yang tak berdaya, sakit-sakitan dan beban dalam pembangunan. Penduduk Iansia sebagai aset pembangunan diharapkan mampu memberikan kontribusi bagi keluarganya. Penduduk lansia yang bekerja tentunya tidak dapat disamakan dengan penduduk usia muda karena kondisi fisik, mental dan sosial mereka banyak yang mengalami penurunan. Dengan demikian banyak faktor yang terkait dengan kondisi tersebut diatas yang dianggap mempengaruhi kecenderungan penduduk lansia berpartisipasi dalam pasar kerja di kota Mataram. Faktor-faktor tersebut adalah pendidikan penduduk lansia, kesehatan lansia, status perkawinan lansia, jumlah tanggungan lansia, jenis kelamin lansia dan jaminan hari tua

\section{Tujuan Dan Kegunaan Penelitian}

Tujuan dari kajian ini adalah untuk mengetahui pengaruh faktor pendidikan, kesehatan, status perkawinan, jumlah tanggungan, jenis kelamin dan jaminan hari tua (pensiun) penduduk lansia memilih berpartisipasi dalam pasar kerja di kota Mataram. Sedangkan kegunaan 
dari penelitian ini adalah dapat dijadikan sebagai :

Bahan informasi bagi pengambil kebijakan terutama yang berkaitan dengan kependudukan . Mengatur komposisi penduduk, membuka kesempatan kerja yang luas bagi penduduk lansia, menyiapkan sarana dan prasarana bagi penduduk lansia agar mereka merasa nyaman, aman dan menjadi kota yang ramah bagi penduduk lansia.

\section{METODE PENELITIAN}

Jenis penelitian yang digunakan adalah penelitian eksplanatif sedangkan lokasi penelitian di Kota Mataram dengan pertimbangan bahwa Kota Mataram merupakan salah satu dari 14 kota yang ada di Indonesia yang dijadikan sebagai contoh kota yang ramah terhadap penduduk lansia. Disamping itu juga terjadinya peningkatan jumlah penduduk lansia dari tahun 2014- 2016. Penelitian ini menggunakan rancangan sampel non probabilitas, dimana penarikan sampel tidak penuh dilakukan dengan menggunakan hukum probabilitas, artinya bahwa tidak semua unit populasi memiliki kesempatan untuk dijadikan sampel penelitian. Hal ini karena sifat populasi itu sendiri yang hetrogen sehingga terdapat diskriminasi tertentu dalam unit-unit populasi.(Burhan B, 2011, 119)

Dalam penelitian ini populasinya adalah seluruh penduduk lansia di Kota Mataram yang berumur 60 tahun keatas baik laki-laki maupun prempuan yang tidak berada dalam satu rumah tangga,baik yang bekerja maupun tidak bekerja . Jumlah keseluruhan responden 60 penduduk lansia yang tersebar pada 6 kecamatan yang ada di kota Mataram yaitu kecamatan Ampenan, kecamatan Sekarbela, kecamatan Mataram, kecamatan Selaparang, kecamatan Cakranegara dan kecamatan Sandubaya Identifikasi Variabel

Variabel-variabel yang digunakan dapat diidentifikasikan sebagai berikut :

1. Kecenderungan penduduk lansia berpartisipasi dalam pasar kerja

2. Pendidikan penduduk lansia

3. Kesehatan penduduk lansia

4. Status perkawinan penduduk lansia

5. Jumlah tanggungan keluarga

6. Jenis kelamin

7. Tunjangan hari tua/pensiun

\section{Klasifikasi Variabel}

Variabel-variabel yang telah diidentifikasikan, selanjutnya di klasifikasikan menjadi : 
1. Variabel terikat yaitu variabel yang dapat dipengaruhi oleh variabel lain. Dalam penelitian ini variabel terikatnya adalah kecenderungan penduduk lansia berpartisipasi dalam pasar kerja.

2. Variabel bebas yaitu variabel yang dapat mempengaruhi variabel lain. Dalam penelitian ini variabel bebasnya adalah pendidikan penduduk lansia,kesehatan penduduk lansia, status perkawinan penduduk lansia, jumlah tanggungan keluarga ,jenis kelamin dan jaminan hari tua /pensiun

\section{Definisi Operasional Variabel}

1. Kecenderungan penduduk lansia berpartisipasi dalam pasar kerja. $Y=1$ dan tidak berpartisipasi dalam pasar kerja $\mathrm{Y}=0$

2. Pendidikan penduduk lansia adalah pendidikan yang pernah ditempuh secara formal yg dinyatakan dalam satuan tahun.

3. Kesehatan penduduk lansia didefinisikan sebagai kondisi dimana penduduk lansia dalam keadaan sehat $X=1$ dan penduduk lansia dalam keadaan tidak sehat $\mathrm{X}=0$
4. Status perkawinan sebagai bagian dari karakteristik sosial umumnya meliputi kategori status kawin $\mathrm{X}=$ 1 dan janda/duda $X=0$

5. Jumlah tanggungan penduduk lansia adalah banyaknya orang yang berada dalam rumah tangga tersebut dan makan dalam satu dapur dinyatakan dalam satuan orang

6. Jenis kelamin penduduk lansia adalah identitas dalam kependudukan yang dinyatakan dalam jenis kelamin laki-laki $X=1$ dan jenis kelamin Prempuan $X=0$

7. Jaminan hari tua /pensiun didefinisikan sebagai penghargaan terhadap pekerja yang diterima setelah masa purna tugas (pensiun) $X=1$ (ada jaminan) dan tidak ada jaminan $(X=0)$

Jenis data yang digunakan adalah data primer dan data Skunder. Data primer diperoleh dengan melakukan wawancara langsung kepada responden Sedangkan data skunder diperoleh dari instansi terkait antara lain, BPS Kota Mataram, Dinas Kependudukan dan lain-lainya

\section{Prosedur Analisis}

Model analisis dalam penelitian ini menggunakan Model Regresi Logistik (MRL). MRL adalah prosedur pemodelan 
yang diterapkan untuk memodelkan variabel respon $(\mathrm{Y})$ yang bersifat kategori berdasarkan satu atau lebih variabel prediktor $(X)$, baik itu yang bersifat kategori maupun kontinu. Terkait dengan variabel respon terdiri dari 2 kategori yaitu $Y=1$ (berpartisipasi), dan $Y=0$ (tidak berpartisipasi), dengan demikian maka metode MRL 1.

Terkait dengan objek penelitian ini, karena terdapat 2 kategori yang mengakibatkan variabel respon y berdistribusi Bernoulli. Fungsi distribusi peluang untuk $\mathrm{y}$ dengan parameter $\mathrm{V}$ adalah $P(Y=y)=\gamma \quad y(1-\gamma) 1-y$ dengan $y=0,1$. Sehingga probabilitas untuk masingmasing kategori adalah $P(Y=1)=\gamma$ dan $P(Y=0)=1-\gamma$ dengan $E(y)=\gamma, 0 \leq \gamma \leq 1$. Secara umum model probabilitas regresi logistik dengan melibatkan beberapa variabel prediktor (X) dapat diformulasikan sebagai berikut.

$E(y \mid x)=\frac{e^{(\beta 0+\beta 1 \times 1+\beta 2 \times 2+\beta 3 \times 3+\beta 4 \times 4+\beta 5 \times 5+\beta 6 \times 6}}{1+e^{(\beta 0+\beta 1 \times 1+\beta 2 \times 2+\beta 3 \times 3+\beta 4 \times 4+\beta 5 \times 5+\beta 6 \times 6+}}(1)$

Fungsi $y(x)$ merupakan fungsi non linier sehingga perlu dilakukan transformasi logit untuk memperoleh fungsi yang linier agar dapat dilihat hubungan antara variabel respon (y) dengan variabel prediktornya $(x)$. Bentuk logit dari $Y(x)$ dinyatakan sebagai $g(x)$, yaitu : $g(x)=\ln \left(\frac{\lambda(x)}{1-\lambda(x)}\right)$

(2)

Langkah selanjutnya mensubstiusikan persamaan (1) kedalam persamaan (2), bentuk persamaan tersebut menjadi :

$\ln \left(\frac{\lambda(\mathrm{x})}{1-\lambda(\mathrm{x})}\right)$

$=\beta 0+\beta 1 \times 1+\beta 2 \times 2+\beta 3 \times 3+\beta 4 \times 4+\beta 5 \times 5+\beta 6 \times 6$

Dimana :

$\mathrm{Y}=1$ (memilih berpartisipasi), dan $\mathrm{Y}=0$ (tidak berpartisipasi)

X1 = Pendidikan penduduk lansia (Tahun)

X2 = Kesehatan penduduk lansia, X2 =1 ( sehat), X2 = 0 (tidak sehat)

X3 = Status perkawinan penduduk lansia, X4 = 1 (kawin), X3 = 0 (janda / duda)

jumlah tanggungan penduduk lansia (orang)

X5 = Jenis Kelamin penduduk lansia X5=1 (Laki-laki), X5=0 (prempuan)

$\mathrm{X} 6$ = Adanya jaminan hari tua/pensiun; $X 6=1$ (ada jaminan), $X 6=0$ (tidak ada jaminan)

Salah satu metode untuk mengestimasi parameter di dalam Model Regresi Logistik menggunakan Maximum Estimation Likelihood (MLE). Pada dasarnya metode ini memberikan nilai estimasi parameter $\beta$ dengan cara memaksimumkan fungsi likelihood-nya. Jika fungsi distribusi peluang untuk yi adalah $f(y i)=\gamma$ yi $(1-\gamma) 1-y i$, maka fungsi 
likelihood untuk $\mathrm{n}$ pengamatan independen adalah :

$$
\begin{gathered}
\mathrm{L}(\beta 0, \beta 1, \beta 2, \beta 3, \beta 4, \beta 5, \beta 6) \\
=\prod_{\mathrm{i}=1}^{\mathrm{n}}\left\{[\lambda(\mathrm{xi})]^{\mathrm{yi}}[1\right. \\
-\lambda(\mathrm{xi})]^{1-\mathrm{yi}\}} \\
=\prod_{\mathrm{i}=1}^{\mathrm{n}}\left\{\left[\frac{\lambda(\mathrm{xi})}{1-\lambda(\mathrm{xi})}\right]^{\mathrm{yi}}[1-\lambda(\mathrm{xi})]\right\} \\
=\left[\frac{\lambda(\mathrm{xi})}{1-\lambda(\mathrm{xi})}\right]^{\mathrm{yyi}}[1-\lambda(\mathrm{xi})]^{\mathrm{n}}
\end{gathered}
$$

Berdasarkan fungsi likelihood didapatkan In fungsi likelihood-nya sebagai berikut:

$$
\begin{aligned}
& \ln (L(\beta 0, \beta 1, \beta 2, \beta 3, \beta 4, \beta 5, \beta 6,)) \\
& =\ln (\beta 0, \beta 1, \beta 2, \beta 3, \beta 4, \beta 5, \beta 6) \\
& \quad=\ln \left[\pi\left[\left(\frac{\lambda(x i)}{1-\lambda(x i)}\right)^{y i}[1-\lambda(x i)]\right]\right.
\end{aligned}
$$

Estimasi parameter Regresi Logistik diperoleh dari turunan parsial pertama fungsi In likelihood terhadap parameter yang akan diestimasi kemudian disamakan dengan nol.

\section{PEMBAHASAN}

\section{Analisis Hasil Estimasi dan Pengujian Hipotesis}

Sebelum menguraikan hasil estimasi dan pengujian hipotesis, berikut ini dijelaskan kemaknaan dan ketepatan hasil estimasi dari variabel penjelas terhadap model empiris. Seperti diketahui bahwa tidak terjadinya hubungan/ketergantungan baik secara nyata maupun secara sempurna di antara variabel bebas, yang salah satu pengukurnya adalah berdasarkan nilai standar error. Implikasi yang ditimbulkan dari terpenuhinya syarat tidak terjadinya hubungan/ketergantungan di antara variabel penjelas ini adalah bahwa variabel bebas yang mampu memberikan nilai ekspektasi yang signifikan. Hasil estimasi parameter model dapat dilihat pada Tabel 1. Berdasarkan nilai standard error (S.E) setiap variabel bebas diketahui bahwa tidak terdapat nilai yang melebihi 2 sehingga dapat dikatakan tidak terdapat persoalan ketergantungan yang kuat antara satu variabel bebas yang satu dengan variabel yang lainnya di dalam model tersebut.

Pengolahan data penelitian dilakukan dengan menggunakan program atau soft ware statistik yakni program SPSS versi IBM 20.0. Hasil estimasi model regresi logistik di sajikan dalam tabel 1 berikut.

Tabel 1 . Hasil Estimasi Model Logistik

\begin{tabular}{|l|l|l|l|l|l|}
\hline Variabel & Koefisien & $\begin{array}{l}\text { Standar } \\
\text { Error }\end{array}$ & Wald & Sig. & Exp(B) \\
\hline Constant & $-1,492$ & 1,325 & 1,268 & 260 & 225 \\
\hline Pendidikan $(\mathrm{X} 1)$ &, 225 &, 154 & 2,136 & 144 & 1,252 \\
\hline Kesehatan $(\mathrm{X} 2)$ & 3,196 & 1,282 & 6,210 & 013 & 24,436 \\
\hline
\end{tabular}




\begin{tabular}{|l|l|l|l|l|l|}
\hline $\begin{array}{l}\text { Status Perkawinan } \\
(\mathrm{X} 3)\end{array}$ & 1,682 & 1,694 &, 986 &, 321 & 5,378 \\
\hline $\begin{array}{l}\text { Jumlah Tanggungan } \\
(\mathrm{X} 4)\end{array}$ &, 386 &, 305 & 1,609 &, 205 & 1,472 \\
\hline Jenis Kelamin (X5) & $-2,521$ & 1,737 & 2,106 & 147 & 080 \\
\hline Pensiunan (X6) & $-5,929$ & 2,112 & 7,881 &, 005 &, 003 \\
\hline
\end{tabular}

Sumber : Data Primer, Diolah

Hasil estimasi model logit, dapat diungkapkan melalui persamaan berikut. $\operatorname{Ln}[\mathrm{p} / 1-\mathrm{p}]=-1,492+0,225$ Pendidikann + 3,196 Kesehatan $+1,682$ Status Perkawinan + 0,386 Jumlah Tanggungan 2,521 Jenis Kelamin - 5,929 Pensiunan

Berdasarkan tabel di atas dari seluruh variabel pengamatan sesuai dengan permasalahan dalam penelitian serta hipotesis yang akan dibuktikan kebenarannya. Adapun variabel yang dimaksud adalah pendidikan (X1), kesehatan (X2), status perkawinan (X3), jumlah tanggungan (X4), jenis kelamin (X5), dan pensiunan (X6) yang berpengaruh terhadap memilih pekerjaan pada sektor formal(Y) di Kota Mataram. Berikut akan dilakukan pengujian hipotesis dan dilanjutkan dengan intepretasi hasil estimasi.

Berdasarkan tabel 1 di atas dapat diungkapkan bahwa nilai statistik dari masing-masing variabel bebas yang berpengaruh secara signifikan pada $\alpha 5$ persen adalah kesehatan (X2 dan pensiunan (X6), dengan nilai Wald statistiknya untuk kesehatan (X2) sebesar 6,210

(sig $=0,013$ pensiunan (X6), sebesar 7,881 $(\operatorname{sig}=0,005)$, Dengan demikian bahwa yang mempengaruhi responden dalam penelitian ini guna memutuskan untuk berpartisipasi dalam pasar kerja di Kota Mataram ditentukan oleh kesehatan dan pensiunan.

Adapun pendidikan (X1), status perkawinan (X3), jumlah tanggungan (X4), dan jenis kelamin (X5), adalah tidak berpengaruh nyata terhadap keputusan berpartisipasi dalam pasar kerja di Kota Mataram. Yang ditandai oleh nilai statistiknya yang tidak signifikan pada $\alpha 5$ persen, yaitu pendidikan (X1) sebesar 2,136(sig=0,144), status perkawinan (X3) sebesar 0, 986(sig=0,321), jumlah tanggungan (X4) sebesar 1,609 (sig=0,205), dan jenis kelamin (X5) sebesar 2,106 (sig=0,147). 
Dalam melakukan interpretasi koefisien-koefisien dalam model regresi logit maka diaplikasikan dalam odd ratio (rasio kecenderungan). Rasio Odd ditulis sebagai B atau Exp (B). Rasio Odd digunakan untuk mengetahui kecenderungan peluang suatu variabel. Di sisi lain, nilai Rasio Odd (OR) setiap variabel digunakan untuk menginterpertasikan hubungan variabel dependen dengan seluruh variabel independen. Pengaruh dari masingmasing variabel tersebut dapat dideskripsikan dengan melihat variabel bebasnya $(\operatorname{Exp}(B))$, yaitu sebagai berikut.

1. Nilai OR variabel pendidikan adalah sebesar 1,252 bermakana bahwa setiap kenaikan tingkat pendidikan akan menaikkan keputusan penduduk lansia berpartisipasi dalam pasar kerja di kota Mataram sebesar 1,252 kali

2. Nilai OR variabel kesehatan adalah sebesar 24,436 bermakana bahwa keputusan penduduk lansia berpartisipasi dalam pasar kerja di kota Mataram dengan kondisi sehat sebesar 24,436 kali dibandingkan dengan penduduk lansia yang tidak sehat

3. Nilai OR variabel status perkawinan adalah sebesar 5,378 bermakna keputusan penduduk lansia berpartisipasi dalam pasar kerja di kota Mataram dengan status menikah sebesar 5,378 kali dibandingkan dengan yang tidak/belum menikah atau janda dan duda.

4. Nilai OR variabel jumlah tanggungan adalah sebesar 1,472 bermakana bahwa setiap kenaikan jumlah tanggungan akan menaikkan keputusan penduduk lansia berpartisipasi dalam pasar kerja di kota Mataram sebesar 1,472 kali

5. Nilai OR variabel jenis kelamin adalah sebesar 0,080 bermakana bahwa keputusan penduduk lansia berpartisipasi dalam pasar kerja di kota Mataram dengan jenis kelamin laki-laki sebesar 0,080 kali dibandingkan dengan penduduk lansia yang berjenis kelamin prempuan

6. Nilai OR variabel pensiunan adalah sebesar 0,003 bermakna bahwa keputusan penduduk lansia berpartisipasi dalam pasar kerja di kota Mataram yang memiliki pensiun sebesar 0,003 kali dibandingkan dengan penduduk lansia yang tidak memiliki pensiun 
Dalam penelitian ini beberapa hal mendasar dapat diungkapakan bahwa kondisi kesehatan lansia dan adanya jaminan hari tua atau pensiunan menjadi pertimbangan yang utama dalam memutuskan berpartisipasi dalam pasar kerja di kota Mataram, disamping variabel lain seperti pendidikan, status perkawinan, jumlah tanggungan, dan jenis kelamin.

\section{Ketepatan Model}

Analisis terhadap keterkaitan antara variabel independen (bebas) dengan variabel dependen (terikat) yang menentukan ketepatan atau presisi model logit yang digunakan dalam analisis ini. Berdasarkan hasil pengolahan data diperoleh nilai Chi-Square sebesar 39,772 dengan tingkat signifikansi 0,00 . Dengan demikian dapat disimpulkan bahwa presisi atau kaitan antar variabel pengamatan dalam model kecenderungan penduduk lansia berpartisipasi dalam pasar kerja di Kota Mataram pada a 5 persen adalah adalah terbukti dan signifikan.

Salah satu indikator untuk mengukur ketepatan model adalah dengan koefisien determinasi $\left(R^{2}\right)$. Pengukuran ketepatan model berdasarkan nilai $\mathrm{R}^{2}$ adalah menggunakan nilai $\mathrm{R}^{2}$ dari Cox and Snell dan $\mathrm{R}^{2}$ Nagelkerke. Nilai $\mathrm{R}^{2} \mathrm{Cox}$ and Snell adalah sebesar 0,485 , sedangan nilai $R^{2}$ Nagelkerke adalah sebesar 0,696. Mengacu kepada Washington, et al. (2003) dijelaskan bahwa pada model pilihan dengan model logistik, semakin tinggi nilai pseudo $\mathrm{R}^{2}$ (the goodness of fit),semakin baik model yang disusun.Akan tetapi hal ini tidak selalu tepat. O’Donneldan Connor (2002) menyatakan bahwa secara praktis nilai tersebut dapat diabaikan karena untuk model regresi logistik ini tidak ada nilai baku pseudo $\mathrm{R}^{2}$ yang dapat dijadikan sebagai acuan kelayakan model. Nilai ini mempunyai batas atas baik secara teoritis dan empiris yang selalu kurang dari satu. Oleh karena itu digunakan cara lain untuk menentukan kelayakan model yaitu dengan uji Hosmerand Lemeshow (H-L test).

Uji kelayakan model atau model goodness of fit dilakukan dengan menggunakan prinsip Hosmer and Lameshow (H-L test). Jika nilai uji H-L sama atau kurang dari 5 persen berarti ada perbedaan yang signifikan antara model dengan nilai observasinya, dimana kelayakan model tidak baik karena model dianggap tidak bisa memprediksi nilai observasinya. Jika nilai statistik Hosmer and Lameshow's Goodness of Fit lebih besar dari 5 persen berarti model mampu untuk memprediksi nilai observasinya 
dengan kepercayaan 95 persen. Nilai signifikansi uji Hosmerand Lameshow $(\mathrm{H}-$ L) adalah 1,389 dengan nilai $p$ sebesar 0,994 karena chi square tidak signifikan ( $p$ $>0,05$, maka dapat disimpulkan probabilita yang diprediksi sesuai dengan probabilita yang diobservasi . Dengan kata lain tidak ada perbedaan antara model dengan data sehingga model dapat dikatakan fit

\section{ANALISIS DAN PEMBAHASAN}

\section{Pendidikan dan Kecenderungan}

Penduduk Lansia Berpartisipasi Dalam

\section{Pasar Kerja}

Untuk variabel pendidikan (X1), dari hasil uji statistiknya tidak berpengaruh nyata terhadap kecenderungan penduduk lansia berpartisipasi dalam pasar kerja di Kota Mataram. Yang ditandai oleh nilai statistiknya yang tidak signifikan pada $\alpha 5$ persen, yaitu sebesar 2,136(sig=0,144). Variabel pendidikan dengan nilai OR sebesar 1,252. bermakana bahwa setiap kenaikan tingkat pendidikan akan menaikkan keputusan penduduk lansia berpartisipasi dalam pasar kerja di kota Mataram sebesar 1,252 kali

Dari hasil uji statistik dimana variabel pendidikan tidak berpengaruh nyata terhadap kecenderungan penduduk lansia berpartisipasi dalam pasar kerja di
Kota Mataram. Hasil uji ini memberikan arti bahwa pendidikan lansia bukan merupakan variabel yang berpengaruh nyata dalam lansia berpartisipasi pd pasar kerja. Lansia sebagai bagian dari penduduk mempunyai suatu keunikan tersendiri. Disaat usia yg semakin lanjut dengan kondisi yang tidak muda dan produktivitas mulai menurun. Berdasarkan pendidikan terlihat relatif rendahnya pendidikan dari lansia bekerja di kota Mataram dimana sekitar 58, 33 persen dengan jenjang pendidikan SD dan 25 persen dengan pendidikan SMA dan Sarjana. Lansia dengan pendidikan yang tinggi (SMA keatas) adalah lansia yg dulunya mempunyai pekerjaan pada sektor formal dengan memiliki jaminan hari tua /pensiun. Sedangkan Lansia dengan jenjang pendidikan SD dan SMP cenderung bekerja pada sektor informal.

Kondisi Kesehatan dan Kecenderungan Penduduk Lansia Berpartisipasi Dalam Pasar Kerja

Untuk variabel kesehatan (X2), dari hasil uji statistiknya berpengaruh secara nyata terhadap kecenderungan penduduk lansia berpartisipasi dalam pasar kerja di Kota Mataram pada $\alpha 5$ persen, dengan nilai Wald statistiknya sebesar 6,210(sig = 0,013). Nilai OR variabel kesehatan adalah sebesar 24,436 bermakana bahwa 
keputusan penduduk lansia berpartisipasi dalam pasar kerja di kota Mataram dengan kondisi sehat sebesar 24,436 kali dibandingkan dengan penduduk lansia yang kurang/tidak sehat. Dari hasil uji statistik dimana variabel kesehatan berpengaruh nyata terhadap kecenderungan penduduk lansia berpartisipasi dalam pasar kerja di Kota Mataram. Hasil uji dengan slope yang positip ini memberikan arti bahwa semakin baik kondisi kesehatan lansia maka akan semakin tinggi partisipasi dalam pasar kerja di kota Mataram. Didukung dengan hasil perhitungan curahan jam kerja yang mencerminkan partisipasi lansia dalam pasar kerja di kota Mataram, 90 persen responden ( 54 orang) mempunyai curahan jam kerja lebih besar dari 35 jam perminggu dan hanya 10 persen (6 orang) yang bekerja kurang dari 35 jam perminggu. Berdasarkan Susenas tahun 2015 angka kesakitan lansia sebesar $28,62 \%$, artinya bahwa dari setiap 100 orang lansia terdapat sekitar 28 orang diantaranya mengalami sakit. Bila dilihat berdasarkan tipe daerah,derajat kesehatan lansia yang tinggal di perkotaan cenderung lebih baik daripada lansia yang tinggal di perdesaan .
Status Perkawinan dan Kecenderungan Penduduk Lansia Berpartisipasi Dalam Pasar Kerja

Dari hasil uji statistik variabel status perkawinan (X3) tidak berpengaruh nyata terhadap kecenderungan penduduk lansia berpartisipasi dalam pasar kerja di Kota Mataram. Yang ditandai oleh nilai statistiknya yang tidak signifikan pada $\alpha 5$ persen, yaitu sebesar $0,986($ sig $=0,321)$. Variabel status perkawinan dengan nilai OR sebesar 5,378 bermakna keputusan penduduk lansia berpartisipasi dalam pasar kerja di kota Mataram dengan status menikah sebesar 5,378 kali dibandingkan dengan yang tidak/belum menikah atau janda dan duda. Terkait dengan status perkawinan lansia, dari 60 responden sebesar 68,33 persen (41 orang) berstatus menikah dan 31,67 persen (19 orang) belum menikah (janda dan duda). Menurut jenis kelamin, pola status perkawinan penduduk lansia lakilaki berbeda dengan lansia perempuan. Lansia perempuan lebih banyak yang berstatus cerai sebesar 26,67 persen (16 orang janda) dan lansia laki-laki berstatus cerai hanya 5 persen ( 3 orang duda). Sedangkan lansia laki-laki lebih banyak yang berstatus kawin sebesar 50 persen (30 orang). Satu hal yang menarik dari status perkawinan lansia adalah 
persentase yang cukup tinggi dari lansia perempuan yang berstatus cerai. Kemungkinan kondisi ini terjadi disebabkan sebagian besar perempuan setelah cerai tidak kawin lagi dalam jangka waktu yang relatif lama. Sebaliknya lansia laki-laki yang bercerai umumnya segera kawin lagi. Gambaran ini menunjukkan bahwa perempuan mempunyai sikap yang lebih mandiri dan mampu mengurusi dirinya sendiri.

\section{Jumlah Tanggungan dan Kecenderungan}

Penduduk Lansia Berpartisipasi Dalam Pasar Kerja

Untuk variabel jumlah tanggungan (X4 ) tidak berpengaruh nyata terhadap Kecenderungan Penduduk Lansia Berpartisipasi Dalam Pasar Kerja Yang ditandai oleh nilai statistiknya yang tidak signifikan pada a 5 persen, sebesar 1,609 (sig=0,205). Nilai OR variabel jumlah tanggungan adalah sebesar 1,472 bermakana bahwa setiap kenaikan jumlah tanggungan akan menaikkan keputusan penduduk lansia berpartisipasi dalam pasar kerja di kota Mataram sebesar 1,472 kali. Kondisi ini memberikan gambaran bahwa semakin besar jumlah tanggungan keluarga akan mendorong kepala rumah (penduduk lansia) berpartisipasi dalam pasar kerja di kota Mataram. Terkait jumlah tanggungan, 65 persen rumah tangga lansia (39 orang) menanggung 0-2 orang dan 35 persen rumah tangga lansia (21 orang) menanggung 3 atau lebih anggota keluarganya.

Jenis Kelamin dan Kecenderungan Penduduk Lansia Berpartisipasi Dalam Pasar Kerja

Variabel jenis kelamin (X5) ) tidak berpengaruh nyata terhadap Kecenderungan Penduduk Lansia Berpartisipasi Dalam Pasar Kerja yang ditandai oleh nilai pada $\alpha 5$ persen dengan nilai Wald statistiknya sebesar 2,106 $(\operatorname{sig}=0,147)$ Nilai OR variabel jenis kelamin adalah sebesar 0,080 bermakana bahwa keputusan penduduk lansia berpartisipasi dalam pasar kerja di kota Mataram dengan jenis kelamin laki-laki sebesar 0,080 kali dibandingkan dengan penduduk lansia yang berjenis kelamin prempuan. Menurut Simanjuntak (1985 : 24) curahan jam kerja setiap orang berbeda atau tidak sama , tergantung kondisi rumah tangganya masing-masing.Rumah tangga sebagai penyedia tenaga kerja akan menawarkan anggota keluarganya dalam pasar kerja dengan berbagai pertimbangan seperti, ingin lebih mengurus rumah tangga dirumah. Pekerja lanjut usia laki-laki lebih besar untuk bekerja full-time ( $\geq 35$ jam perminggu) 
dibandingkan dengan pekerja lansia perempuan memperlihatkan gambaran, bahwa anggota keluarga yaitu anak merasa kasihan terhadap ibu mereka yang sudah masuk lanjut usia untuk tetap mencurahkan banyak waktunya dipasar kerja. Hal tersebut mempengaruhi sisi penawaran pekerja lansia perempuan untuk bekerja part-time $1<35$ jam perminggu). Berbeda dengan pekerja lanjut usia laki-laki yang fungsinya sebagai pencari nafkah utama keluarga, merasa berharga mencurahkan waktunya lebih banyak di pasar kerja. Sebagai bentuk tanggung jawab kepala keluarga dalam mencari pendapatan dicerminkan dengan penawaran pekerja lansia laki-laki untuk bekerja full-time ( $\geq 35$ jam perminggu)

\section{Jaminan Hari Tua/ Pensiun dan Kecenderungan Penduduk Lansia Berpartisipasi Dalam Pasar Kerja}

Untuk variabel Pensiun (X6), dari hasil uji statistiknya berpengaruh secara nyata terhadap kecenderungan penduduk lansia berpartisipasi dalam pasar kerja di Kota Mataram pada $\alpha 5$ persen, dengan nilai Wald statistiknya sebesar 7,881(sig = $0,005)$. Nilai OR variabel pensiunan adalah sebesar 0,003 bermakna bahwa keputusan penduduk lansia berpartisipasi dalam pasar kerja di kota Mataram yang memiliki pensiun sebesar 0,003 kali dibandingkan dengan penduduk lansia yang tidak memiliki pensiun

Dari hasil uji statistik dimana variabel pensiun berpengaruh nyata terhadap kecenderungan penduduk lansia berpartisipasi dalam pasar kerja di Kota Mataram.. Hasil uji dengan slop yang positip ini memberikan arti bahwa dengan dimilikinya jaminan hari tua/pensiun maka akan semakin tinggi partisipasi dalam pasar kerja di kota Mataram. Kondisi ini terjadi karena rumah tangga lansia di perkotaan masih belum sejahtera, yang mendorong mereka tetap bekerja di masa tua untuk memenuhi kebutuhan hidup mereka serta tuntutan ekonomi serta biaya hidup yang lebih besar di daerah perkotaan membuat pekerja lansia di perkotaan cenderung memiliki probabilitas lebih besar untuk bekerja

\section{KESIMPULAN DAN SARAN}

\section{Kesimpulan}

Dari latar belakang dan pembahasan dapat disimpulkan hal-hal sebagai berikut

1. Dalam penelitian ini beberapa hal mendasar dapat diungkapakan bahwa kondisi kesehatan lansia dan adanya jaminan hari tua atau pensiunan menjadi pertimbangan yang utama dalam memutuskan berpartisipasi 
dalam pasar kerja di kota Mataram, disamping variabel lain seperti pendidikan, status perkawinan, jumlah tanggungan, dan jenis kelamin.

2. Secara umum kondisi kesehatan responden lansia di kota Mataram berada dalam kondisi sehat dengan curahan jam kerja yang cukup panjang (lebih dari 35 jam perminggu)

3. Jenis pekerjaan responden lansia di kota Mataram lebih banyak pada sektor informal

4. Pendapatan yang diterima oleh responden lansia secara rata-rata melebihi upah minimun kota Mataram
Saran

Terkait dengan kajian ini beberapa hal yang dapat disarankan adalah sebagai berikut :

1. Seiring dengan meningkatnya Usia harapan hidup di Kota Mataram perlu dilakukan secara intensif untuk membekali penduduk lansia dengan berbagai kegiatan yang produktif agar dapat mengisi aktifitas sehari-hari

2. Kawasan ramah lansia di kota Mataram harus segera diimplementasikan agar lansia merasa nyaman dan aman serta dapat terus berkontribusi dalam pembangunan di Kota Mataram

\section{DAFTAR PUSTAKA}

Arfida BR, 2003, Ekonomi Sumber Daya Manusia, Ghalia Indonesia, Jakarta

Affandi, M.,2009 ,Faktor-faktor yang Mempengaruhi Penduduk Lanjut Usia Memilih Untuk Bekerja. Journal of Indonesian Applied Economics Vol. 3 No. 2, Oktober, Fakultas Ekonomi Universitas Brawijaya

Badan Pusat Statistik. Statistik Penduduk Lanjut Usia 2013. Jakarta: BPS; 2014

Badan Pusat Statistik. Statistik Penduduk Lanjut Usia 2014. Jakarta: BPS; 2015

Burhan Bungin, 2011, Metodologi Penelitian Kuantitatif, Kencana Prenada Media Group, Jakarta

Benyamin Davis, 2013, Menemukan Landas Pijak Bersama Bagi Penanganan Isu-Isu Penuaan Penduduk, Yogyakarta 
Bondan Sikoki, 2013, Penuaan Penduduk di Indonesia ; Tantangan ke Depan , Yogyakarta

Heryanah, 2015, Ageing Population dan Bonus Demografi Kedua Di Indonesia, Jurnal Populasi Volume 23 Nomor 2

Mudrajad Kuncoro, 1997, Ekonomi Pembangunan: Teori, Masalah dan Kebijakan, YKPN, Yogyakarta,

Mulyadi S, 2003, Ekonomi Sumber Daya Manusia Dalam Perspektif Pembangunan, PT RajaGrafindo Persada, Jakarta

Nazir, Moh, 1999, Metode Penelitian, Ghalia Indonesia, Jakarta

Ni Kadek Andini, Desak Pt Eka Nilakusumawati, Made Susilawati, Faktor- faktor Yang Mempengaruhi Penduduk Lanjut Usia Masih Bekerja,Jurnal Piramida Vol. IX No.1, Juli 2013.

Ni Putu Rusmala Dewi K, I Kt. Sudibia, Pengaruh Variabel Sosial Demografi dan Sosial Ekonomi Terhadap Partisipasi Kerja Penduduk Lanjut Usia, Jurnal EP Unud, Vol. 3 No.6, Juni 2014

Rusli Said, 1982, Pengantar Ekonomi Kependudukan , LP3ES, Jakarta

Soekidjo N, 2009, Pengembangan Sumber Daya Manusia, Rineka Cipta,Jakarta

Sonny Sumarsono, 2009, Teori dan Kebijakan Publik Ekonomi Sumber Daya Manusia, Graha IImu, Yogyakarta

Sudarwan Danim, 2004, Ekonomi Sumber Daya Manusia, CV Pustaka Setia, Bandung

Sri Sultan Hamengku Buwono X, 2013, Penduduk Lanjut Usia Sebagai Aset, Bukan Beban, Yogyakarta

Tiwi Setyawati, Analisis faktor sosial ekonomi dan demografi pekerja lanjut usia di wilayah Jawa Tengah (studi kasus data sakernas 2007)

Wirakartakusumah, M. Djuhari, Hisar Sirait, dan Zainul Hidayat. 1996. Pelibatan Penduduk Usia Lanjut dalam Keluarga. Jakarta: Lembaga Demografi Fakultas Ekonomi UniversitasIndonesia 